\title{
Patient experiences in a public primary health care clinic: A South African case study
}

\author{
ÓSCAR BRITO FERNANDES ${ }^{1,2 *}$ (1), MUKHETHWA NETSHIOMBO ${ }^{1}$ (0),

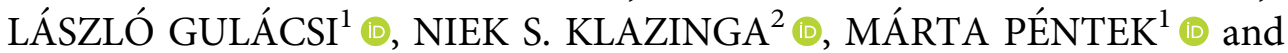 \\ PETRA BAJI ${ }^{1}$
}

\footnotetext{
${ }^{1}$ Department of Health Economics, Corvinus University of Budapest, Budapest, Hungary

${ }^{2}$ Department of Public and Occupational Health, University of Amsterdam, Amsterdam, The Netherlands
}

Received: May 12, 2020 • Revised manuscript received: June 17, 2020 • Accepted: June 19, 2020

Published online: July 30, 2020

(C) 2020 The Author(s)

\begin{abstract}
The South African Ministry of Health has recognized experiences of care as key to strengthen patient-centred care. This case study aims to measure patient-reported experiences of care at a clinic in South Africa, and its associations with the respondents' sociodemographic characteristics. A survey was conducted in 2019 on a convenience sample of 179 respondents. Questions on experiences of care were based on a standardised set of questions by the Organization for Economic Co-operation and Development (OECD). Logistic regression was used to examine the effects of respondents' characteristics on their experiences. The proportion of respondents who reported that a nurse spent adequate time with them during consultation was significantly higher among literate respondents (92.3 vs. 79.5\%). Those who reported past negative experiences were significantly more likely to report a positive experience in regard to perceiving adequate consulting time (odds ratio $=3.865$, with a $95 \%$ confidence interval between 1.555 and 9.607), receiving easy-to-understand explanations (4.308; 1.665-11.145), being given the opportunity to ask questions $(2.156 ; 1.013-4.589)$ and shared decision-making $(3.822 ; 1.728-8.457)$. The results can spur comparisons with other clinics in a similar setting and inform key stakeholders on aspects of the care experience that need greater improvement within the national framework for quality and safety assurance and patient experience measurement.
\end{abstract}

\section{KEYWORDS}

primary health care, patient experiences, patient-centred care, South Africa, Sibasa Clinic

JEL CODES

C83, I19

${ }^{\star}$ Corresponding author. E-mail: obritofernandes@uni-corvinus.hu 


\section{INTRODUCTION}

\subsection{Patient experiences of care}

For more than three decades, increased attention has been placed on developing health systems that are more patient-centric, to allow greater responsiveness to patients' needs, expectations and preferences. Moving health care organizations towards patient-centric and value-based care trajectories is aligned with evidence that links the use and dissemination of patient data across health care organizations to steer patient-driven changes (De Rosis et al. 2020). Consequently, there is an ever-growing use of instruments to capture the voice of patients, typified by patientreported outcome measures (PROMs) and patient-reported experience measures (PREMs) (Coulter 2017; Price et al. 2014).

Greater attention is given to ways of capturing citizens' voices within a value-based care framework. Value-based care encompasses: i) the promotion of value-based pricing, purchasing and use of treatments and health care services in general; ii) enabling communication about treatment options and costs and; iii) minimising the impacts of costs with medicines and other related costs to financial toxicity (also known as catastrophic health expenditure), to which patients with several and severe morbidities are more at risk relative to those without severe diseases (President's Cancer Panel 2018; WHO 2018; Xu et al. 2005). The underlying assumption is that patent-centric and value-based care provide efficiency gains to health care systems in terms of increasing quality life years; greater cost-effectiveness, given patients' adherence to treatment choice where their voice was accounted for; decreased productivity loss and informal care burden and; contribution to employment sustainability. Given these effects, many countries strive for health care reforms, which aim at improving the performance of the health care system. A key component of performance is efficiency, and achieving efficiency gain means getting more value for money, i.e. investments are rewarded by increasing overall health care productivity (Gulácsi - Péntek 2014). Success requires multiple factors, including patient-centric and value-based care, where capturing the perspective of patients (via patient-reported outcome and experience measures) has the potential to inform decision-makers on where efficiency may be gained (Barbazza et al. 2019; Gilmore et al. 2019; Péntek 2019).

Patient experience encompasses all processes across the continuum of care observable by patients and which influence a patient's perception of the care delivered (Price et al. 2014; Wolfe et al. 2014). For example, the Agency for Healthcare Research and Quality (AHRQ) describes patient experience as "several aspects of health care delivery that patients value highly when they seek and receive care, such as getting timely appointments, easy access to information, and good communication with health care provider" (AHRQ 2019). The interaction of many actors and settings makes patient experience a complex multidimensional concept (Sandager et al. 2016), which partly explains why it is difficult to define its core components, and thus, measuring them (LaVela -Gallan 2014).

Notwithstanding, patient experience is an intrinsically relevant dimension of quality of care (Duschinsky - Paddison 2018). There is strong evidence on the association of patient experience with health care quality indicators (Ahmed et al. 2014; Bleich et al. 2009; Doyle et al. 2013; Kingsley - Patel 2017; Llanwarne et al. 2013; Price et al. 2014). For example, two systematic reviews have highlighted that positive experiences of care were associated with a decrease in 
primary and secondary care use (e.g. number of hospital admissions, readmissions and primary care consultations), and greater adherence to prevention and treatment processes (Doyle et al. 2013; Price et al. 2014). On the other hand, poorer experiences of care are often associated with inadequate patient-doctor communication and poorer involvement of patients in decision making, with implications for clinical effectiveness and safety (Bao et al. 2017; Kelly et al. 2019). Given robust evidence on these associations, patient experience has been widely used as a proxy measure for care quality with many different purposes.

The use of PREMs varies across health systems and their purposes at the micro, meso and macro level may be complementary. For example, PREMs data can inform health care teams on the effectiveness of processes of care and provide insights into redesigning care pathways that better address the needs, expectations and preferences of patients (Kingsley - Patel 2017). Also, PREMs have been used for quality accreditation and certification (Fujisawa - Klazinga 2017), payment programs (LaVela - Gallan 2014), and to develop health policies that spur patientcentred care delivery (OECD 2017). Albeit interest in measuring performance data such as patient-reported outcomes and experiences is increasing, these are still underused in decisionmaking processes (Ivankovic et al. 2020).

Data collection on PREMs is maturing differently across Organization for Economic Cooperation and Development (OECD) countries. Contextual factors may partly explain these variations, but also the extent to which some aspects act as barrier for the use of PREMs: sampling, data collection, timeliness of data collection and reporting, type of data, level of data aggregation and data reporting (De Rosis et al. 2020). Thus, instruments that are set forth to collect PREMs data in different health care settings are of utmost importance to assure fit for purpose, streamline data collection, strengthen data quality and comparability, and enhance the actionability of PREMs data. Examples can be drawn from the work of the Picker Institute, the AHRQ's Consumer Assessment of Healthcare Providers and Systems program, the Commonwealth Fund and also the OECD. These organizations have been frontline pioneers in patient experience measurement with standardised tools, which allow for international comparisons and dissemination of good practices (OECD - EU 2019). Their work has positioned PREMs at the fore of patient-centred care and quality improvement initiatives across many countries (Fujisawa - Klazinga 2017). For example, in Hungary, researchers have recently investigated patient experiences with outpatient care on a national representative sample of 1,000 respondents using a set of standardised PREMs questions. A first study focused on forgone medical visits as an important factor of patient-centric care (Lucevic et al. 2019), examining questions regarding the existence of unmet medical needs if patients: (1) reported forgone medical visits due to costs; (2) forgone medical tests and treatment due to costs; (3) unfilled prescriptions for medicine, or skipped doses due to costs; (4) forgone medical visits due to difficulties in travelling. In addition, another study focused on the care experiences of the last outpatient consultation: (1) did the doctor spend enough time with the patient in consultation; (2) did the doctor provide easy to understand explanations; (3) did the doctor give the opportunity to ask questions or raise concerns about care or treatment; (4) did the doctor involve the patient in decisions about care and treatment (Brito Fernandes et al. 2019). Both studies were important in emphasizing the need to collect, analyse and report on these patient-reported data in Hungary, in a consistent manner over time, and to allow cross-national comparisons with other OECD countries, where the same standardised questions have been used. Conversely, measuring PREMS in South Africa is still in its infancy (Manga et al. 2018). 


\subsection{Patient experiences in South Africa}

In South Africa, the Free Health Care policy of 1996 (Monson 2006) has ensured public primary health care (PHC) coverage to all citizens. In that regard, many improvements have been made, for example in access to care (e.g. $90 \%$ of the population now live within $7 \mathrm{~km}$ of a public primary care facility) and in health outcomes (e.g. increased life expectancy and reduction in child and maternal mortality) (McLaren et al. 2014). Despite the backdrop of these milestones, citizens still face a series of challenges, such as low life expectancy at birth, high infant mortality rates, health care professional and medicine shortages, and health professionals' overall limited knowledge about the needs and preferences of patients (OECD 2014, 2019a, 2019b, 2019c).

According to the 2017 General Household Survey, $71.2 \%$ of the population use public providers as a first choice of consultation when in ill-health (Statistics South Africa 2017), with PHC serving as the first point of entry into the health system. The quality of care in PHC facilities is a reoccurring topic that attracts public attention and scrutiny, following strong evidence throughout the years that the health system should be more responsive (e.g. Bresick et al. 2019a, 2019b; Kelly et al. 2019; Peltzer 2009; Peltzer - Phaswana-Mafuya 2012).

We conducted a brief literature review on quality of care in PHC in South Africa. The retrieved articles suggest a growing interest among researchers and government officials about improving quality of care. For example, the growing number of validated versions of the primary care assessment tool (PCAT), which focus on dimensions such as access, continuity, comprehensiveness, coordination and person-centredness (Bresick et al. 2015, 2016; Dullie et al. 2018). Baseline PCAT results in South Africa's Western Cape Province highlighted that a gap exists between the experiences of care reported by patients that used PHC services and the perception of PHC staff regarding the care they provided (Bresick et al. 2016; Mukiapini et al. 2018). These results underpin an increasing interest about patient care experiences, which are key to the implementation of a National Health Insurance scheme, which seeks to reform the current inequitable health system and place an emphasis on patient-centred care (Department of Health 2019a).

In 2017, the South African Ministry of Health published the "National Guideline on conducting Patient Experience of Care Survey in Public Health Establishments," introducing the first national survey on patient experiences in the inpatient and outpatient settings, and in mental health establishments (Department of Health 2017). This very important document showed the Government's commitment to improving quality of care and providing methodological guidance on how to set up a questionnaire survey fit to collect nation-wide data about experiences of care. This initiative followed those of previous ad-hoc evaluations of patient experience such as that of the Chronic Care Assessment of Patient Experience (CCAPE), which was developed as an approach to gauge the care experiences of chronic patients. The survey was designed to measure patient experiences against a set of norms and standards developed by the Health Ministry and the Office of Health Standards and Compliance. The survey focused on the following dimensions: i) dignity; ii) autonomy; iii) confidentiality; iv) prompt attention; v) access to social support networks during care; vi) quality of basic amenities; vii) choice of care provider and; viii) the responsiveness of the health system. The results of this survey aim to inform PHC facilities on how to achieve a standard of care that is equipped to serve the population once the proposed Universal Health Coverage policy is set into law. International 
comparisons are deemed as essential, but limited because of the design of the instruments used.

In addition, parallel to the introduction of the patient experience survey, the South African Health Ministry has set forth a programme: “The Ideal Clinic Realisation and Maintenance plan" (Hunter et al. 2017). This initiative seeks to encourage improvements in PHC facilities (e.g. good infrastructure and adequate staff) and foster greater cooperation among PHC facilities, the private sector and non-governmental organisations to address social determinants of health. In this regard, the Ideal Clinic initiative measures PHC facilities against a set of promulgated norms and standards (e.g. an Ideal Clinic should score an overall average of $70 \%$ in the patient experience of care survey). One of the PHC clinics in South Africa that has been assessed by this initiative is Sibasa Clinic, which is a nurse-led public clinic in the Vhembe District, Limpopo (South Africa). We provide further information about this PHC facility and its context in Box 1.

This study aims to measure patient experiences of care at Sibasa Clinic more in depth and in an internationally comparative manner, regarding patient-nurse communication and patient involvement in decision-making using a standardised set of PREMs, disseminated by the OECD. Furthermore, we aim to assess associations of experiences of care with sociodemographic characteristics of the respondents.

\section{Box 1. Brief description of Sibasa Clinic and its context}

Makwarela, home to Sibasa Clinic, is a small township in Thulamela municipality, which is the second largest municipality in Vhembe District, Limpopo Province. Vhembe district is one of the poorest in South Africa and the education and employment statistics reflect the poor state of affairs: $21.9 \%$ (48.6\% in Makwarela) of the population have a completed Matric (High School Diploma) and 29.9\% (35.8\% in Makwarela) have a paid job (Statistics South Africa 2011).

Thulamela municipality has the highest concentration of health care facilities: 3 district hospitals, 1 referral hospital and 52 PHC facilities that include 49 clinics (one of them being Sibasa Clinic) and 3 community health care centres. In Vhembe, only $39 \%$ of clinics have an Ideal Clinic status, for which Sibasa Clinic applied in 2015 and was denied after failing to meet standards and norms of quality of care.

Sibasa Clinic is a small primary care clinic that serves the population living in the villages of Makwarela, Sibasa, Dzingahe and Miluwani. Based on the 2011 Census data, these villages represent an area of $7.4 \mathrm{~km}^{2}$, with more than 4,200 households and a total population of 15.578 , of which $53 \%$ are women. Monthly, on average, 4,000 people use the services provided at the Sibasa clinic. The clinic provides services during business hours (7am to $6 \mathrm{pm}$ ) from Monday to Friday. Those who have emergencies after hours or on weekends have to seek care elsewhere (24$\mathrm{h}$ clinics or hospitals). The clinic is meant to offer comprehensive services that are promotional, preventative, curative, rehabilitative and palliative. Services offered range from acute and chronic care, to family planning, antenatal and postnatal care, which includes vaccinations for children. The clinic has a staff of 22 , which includes 17 female nurses of varying qualifications, 1 dietician and 1 pharmacy assistant. The other 3 staff member are non-health professionals. The clinic does not have a resident medical doctor, i.e. the clinic is nurse-led. This is not uncommon in South Africa as nurses are trained to be the face of PHC facilities. 


\section{METHODS}

\subsection{Study design, setting, study population and sampling strategy}

In early 2019, a cross-sectional survey was conducted at Sibasa Clinic, South Africa. Given time and cost restraints, a convenience sample was built with adult patients (18 years old and over) who had received health care at Sibasa Clinic before. A total of 179 fully completed questionnaires were retrieved for further analysis. We used two modes of survey administration: self- and interviewer-administered. The latter was used to include those respondents who could not read, as Limpopo's proportion of illiterates is 7\% among young people (age between 15 and 35 years) and 28.7\% among adults (age between 35 and 64 years) (McLaren 2014). In the intervieweradministered survey, the interviewer did not discuss the questions or their meanings with the respondents. Ethical clearance was obtained from the Limpopo Province Research and Ethics Committee of the Premier's office (REC-111513-038). Consent was obtained from all respondents involved.

\subsection{Data collection}

The survey was composed of a set of standardised questions to measure patient-reported experiences with ambulatory care, as suggested by the OECD (Fujisawa - Klazinga 2017). These questions focused on the patient experience with patient-nurse communication and patient involvement in decision-making. These questions were originally in English; hence, we conducted a forward-backward translation to develop a Tshivenda version of the PREMs questions, with the support of a professional translator. This was necessary because almost $90 \%$ of the population is Tshivenda native-speaking. Both the English and the Tshivenda surveys were given to a sample of 10 Tshivenda and English-speaking individuals to complete as a pilot. Issues raised by respondents were reported and discussed with the interviewer, who was the same at all stages of data collection. The Tshivenda survey was found to correspond in content and meaning to the English version, with no culturally sensitive wording.

\subsection{Variables}

Respondents answered the following questions which serve as dependent variables: 1) did the nurse spend enough time with the patient in consultation; 2) did the nurse provide easy-tounderstand explanations; 3 ) did the nurse give an opportunity to ask questions or raise concerns; 4) did the nurse involve the patient in decisions about care and treatment.

All questions had two possible answers: yes/no. These were presented in Tshivenda as Ee/ Hai. The original questions in English language had a multiple point Likert scale as the answer option. In our survey, we decided to simplify the answer options, taking into consideration previous expectations towards respondents' characteristics (e.g. great proportion of illiterate respondents), but also to mimic the binary answer option of the current national survey on patient experiences in PHC facilities.

To assess associations between positive experiences with ambulatory care and respondents' sociodemographic characteristics, we considered the following independent variables: sex (women/men), age group (18-34, 35-64, 65 and over), job status (having a paid job/not having a paid job) and the existence of a past negative experience of care at the clinic (1: had a previous negative experience). 


\subsection{Data analysis}

We used descriptive statistics to describe respondents' characteristics. The chi-square test was used to assess differences in the proportion of participants who had a positive experience by sociodemographic characteristics and existence of a past negative experience at the clinic. Multivariate logistic regression was used to assess associations between respondents' positive experience of care (dependent variable) and sociodemographic characteristics and past negative experience at the clinic. All analyses were conducted in Stata version 16. The level of significance was set at $P<0.05$.

\section{RESULTS}

Our survey resulted in 179 fully completed questionnaires for further analysis (Table 1). The majority of the respondents were women (73.2\%). The average age of the respondents was 36 years old (standard-deviation: 16). Most respondents were aged between 18 and 34 years old (58.1\%), while respondents above 65 years of age accounted for $8.4 \%$ of the sample. The majority of the respondents $(78.8 \%)$ did not have a paid job. Most respondents reported to have had a past negative experience while seeking care at the clinic (77.1\%). The share of interviewadministered questionnaires with illiterate respondents was of $29.1 \%$. The proportion of illiteracy between women and men, and those with and without a paid job did not differ significantly (29.8 vs. $35.4 \%$ and 24.5 vs. $31.1 \%)$.

\subsection{Patient experiences at Sibasa Clinic}

The total proportion of respondents who reported that their nurse spent enough time with them was of $83.2 \%$ (Table 1). Overall, $86.6 \%$ of the respondents reported that the nurse gave easy-tounderstand explanations. The proportion of respondents who reported being given the opportunity to ask questions or raise concerns was of $69.8 \%$. Lastly, $78.8 \%$ of respondents stated being involved in decision-making about their care and treatment.

Our data suggested that the proportion of positive experiences with the time a nurse spent in consultation with a respondent differed significantly by literacy status: those who were literate reported better experience of care (92.3 vs. 79.5\%). Moreover, those who reported previous negative experiences of care at the clinic had significantly better experiences of care regarding a nurse spending enough time in consultation ( 88.4 vs. $65.9 \%)$, providing easy-to-understand explanations (91.3 vs. $70.7 \%)$ and involving the patient in decision-making (84.8 vs. $58.5 \%$ ).

\subsection{Associations of the respondents' sociodemographic characteristics with positive experiences of care}

Women were less likely than men to report positive experiences of care regarding a nurse spending enough time in consultation, giving opportunity to ask questions or raise concerns and in being involved in decision-making (Table 2). Conversely, women were twice as likely than men to report a positive experience regarding a nurse giving easy-to-understand explanations.

In contrast to young people (between 18 and 34 years of age), respondents aged between 35 and 64 years had a greater likelihood of positive experience of care with the duration of the consultation [Odds Ratio $(\mathrm{OR})=1.216$; 95\% Confidence Interval (CI): 0.462-3.198] and being given easy-to-understand explanations $(\mathrm{OR}=2.139 ; 95 \% \mathrm{CI}$ : 0.706-6.482), although the 
Table 1. Proportion of positive experiences of care in Sibasa Clinic by respondents' characteristics

\begin{tabular}{|c|c|c|c|c|c|c|c|c|c|}
\hline & \multirow{2}{*}{$\begin{array}{r}\text { Sample Size } \\
N(\%)\end{array}$} & \multicolumn{2}{|c|}{$\begin{array}{r}\text { Nurse spending enough time } \\
\text { with patient during } \\
\text { consultation }\end{array}$} & \multicolumn{2}{|c|}{$\begin{array}{l}\text { Nurse giving easy-to- } \\
\text { understand explanations }\end{array}$} & \multicolumn{2}{|c|}{$\begin{array}{r}\text { Nurse giving opportunity to } \\
\text { ask questions or raise } \\
\text { concerns }\end{array}$} & \multicolumn{2}{|c|}{$\begin{array}{r}\text { Nurse involving patient in } \\
\text { decisions about care and } \\
\text { treatment }\end{array}$} \\
\hline & & Yes (\%) & $\chi^{2}$ (P value) & Yes (\%) & $\chi^{2}(P$ value $)$ & Yes (\%) & $\chi^{2}$ (P value) & Yes $(\%)$ & $\chi^{2}$ (P value) \\
\hline \multicolumn{10}{|l|}{ Sex } \\
\hline Men & $48(26.8)$ & 89.6 & 1.892 & 79.2 & 3.115 & 70.8 & 0.031 & 83.3 & 0.816 \\
\hline Women & $131(73.2)$ & 80.9 & $(0.169)$ & 89.3 & $(0.078)$ & 69.5 & $(0.860)$ & 77.1 & $(0.366)$ \\
\hline \multicolumn{10}{|c|}{ Age groups (in years) } \\
\hline $18-34$ & $104(58.1)$ & 81.7 & 0.788 & 83.7 & 2.104 & 72.1 & 1.010 & 78.9 & 0.021 \\
\hline $35-64$ & $60(33.5)$ & 86.7 & $(0.674)$ & 91.7 & $(0.349)$ & 68.3 & $(0.604)$ & 78.3 & $(0.990)$ \\
\hline 65 and over & $15(8.4)$ & 80.0 & & 86.7 & & 60.0 & & 80.0 & \\
\hline \multicolumn{10}{|c|}{ Employment status } \\
\hline Has a paid job & $38(21.2)$ & 92.1 & $(0.099)$ & 89.5 & $(0.557)$ & 71.1 & $(0.854)$ & 73.7 & $(0.388)$ \\
\hline \multicolumn{10}{|l|}{ Literacy } \\
\hline Literate & $127(70.9)$ & 92.3 & $4.319 *$ & 92.3 & 2.062 & 63.5 & 1.412 & 84.6 & 1.497 \\
\hline Illiterate & $52(29.1)$ & 79.5 & $(0.038)$ & 84.3 & $(0.151)$ & 72.4 & $(0.235)$ & 76.4 & $(0.221)$ \\
\hline \multicolumn{10}{|c|}{ Previous negative experience } \\
\hline No & $41(22.9)$ & 65.9 & $11.524^{*}$ & 70.7 & $11.523^{*}$ & 58.5 & 3.221 & 58.5 & $13.021 * *$ \\
\hline Yes & $138(77.1)$ & 88.4 & $(0.010)$ & 91.3 & $(0.001)$ & 73.2 & $(0.073)$ & 84.8 & $(<0.001)$ \\
\hline \multicolumn{10}{|c|}{ Overall positive experiences (Yes, \%) } \\
\hline & & & & & & & & & 8 \\
\hline
\end{tabular}

Source: Authors.

Note: $* P$-value $<0.05 ; * * P$-value $<0.001$ 
Table 2. Multivariate logistic regression results to assess associations of respondents' characteristics with positive experiences of care in Sibasa Clinic

\begin{tabular}{|c|c|c|c|c|c|c|c|c|}
\hline & \multicolumn{2}{|c|}{$\begin{array}{r}\text { Nurse spending enough time } \\
\text { with patient during } \\
\text { consultation }\end{array}$} & \multicolumn{2}{|c|}{$\begin{array}{l}\text { Nurse giving easy-to- } \\
\text { understand explanations }\end{array}$} & \multicolumn{2}{|c|}{$\begin{array}{r}\text { Nurse giving opportunity to } \\
\text { ask questions or raise } \\
\text { concerns }\end{array}$} & \multicolumn{2}{|c|}{$\begin{array}{r}\text { Nurse involving patient in } \\
\text { decisions about care and } \\
\text { treatment }\end{array}$} \\
\hline & OR & $(95 \% \mathrm{CI})$ & $\mathbf{O R}$ & (95\% Cl) & $\mathbf{O R}$ & $(95 \% \mathrm{CI})$ & $\mathbf{O R}$ & (95\% Cl) \\
\hline \multicolumn{9}{|l|}{ Sex } \\
\hline Men (Reference) & - & - & - & - & - & - & - & - \\
\hline Women & 0.406 & $(0.142-1.155)$ & 2.232 & $(0.883-5.642)$ & 0.920 & $(0.436-1.939)$ & 0.624 & $(0.252-1.543)$ \\
\hline \multicolumn{9}{|l|}{ Age groups (in years) } \\
\hline 18-34 (Reference) & - & - & - & - & - & - & - & - \\
\hline $35-64$ & 1.216 & $(0.462-3.198)$ & 2.139 & $(0.706-6.482)$ & 0.914 & $(0.441-1.898)$ & 0.841 & $(0.365-1.935)$ \\
\hline 65 and over & 0.551 & $(0.132-2.298)$ & 0.978 & $(0.158-6.045)$ & 0.709 & $(0.223-2.251)$ & 0.840 & $(0.199-3.556)$ \\
\hline \multicolumn{9}{|l|}{ Employment status } \\
\hline No paid job (Reference) & - & - & - & - & - & - & - & - \\
\hline Has a paid job & 2.839 & $(0.770-10.472)$ & 1.374 & $(0.490-3.850)$ & 1.209 & $(0.518-2.825)$ & 0.689 & $(0.281-1.687)$ \\
\hline \multicolumn{9}{|l|}{ Literacy } \\
\hline Literate (Reference) & - & - & - & - & - & - & - & - \\
\hline Illiterate & 2.591 & $(0.866-7.748)$ & 1.506 & $(0.453-5.006)$ & 0.615 & $(0.290-1.307)$ & 1.618 & $(0.652-4.016)$ \\
\hline \multicolumn{9}{|c|}{ Previous negative experience } \\
\hline No (Reference) & - & - & - & - & - & - & - & - \\
\hline Yes & $3.865^{*}$ & $(1.555-9.607)$ & $4.308^{*}$ & $(1.665-11.145)$ & $2.156^{*}$ & $(1.013-4.589)$ & $3.822^{*}$ & $(1.728-8.457)$ \\
\hline
\end{tabular}

Source: Authors.

Note: * P-value < 0.05; OR: Odds ratio; Cl: Confidence interval. 
differences were not statistically significant. Older respondents (65 years old and over) were less likely to report positive experience across all aspects of the care experience. Those who had a paid job were more likely to have a positive experience of care across all attributes of the care experience except that of being involved in decision-making about care and treatment $(\mathrm{OR}=$ 0.689; 95\% CI: 0.281-1.687). In comparison with more educated respondents, those that were illiterate were more likely to have positive experiences of care across all attributes of the care experience except that of being given the opportunity to ask questions or raise concerns (OR: 0.615; 95\% CI: 0.290-1.307). In addition, those who have had a past negative experience at the clinic were significantly more likely to report a positive experience of care across all attributes.

\section{DISCUSSION}

To our knowledge, this is the first study to assess patient experiences of care in South Africa using a set of standardised questions about PREMs endorsed by the OECD, commonly used for cross-national comparisons. We assessed the determinants of positive experiences of care in a public PHC facility (Sibasa Clinic) in Thulamela municipality, South Africa, by means of a cross-sectional study, using a self- or interviewer-administered survey.

Our findings show that a greater proportion of respondents reported positive experiences of care with a nurse providing easy-to-understand explanations (86.6\%); conversely, the least proportion of positive experiences was related to being given an opportunity to ask questions or raise concerns (69.8\%). These shares are aligned with those reported in the 2017 Patient Experience of Care (PEC) survey conducted in 168 randomly selected PHC facilities, where $76.5 \%$ of those respondents reported positive experiences of care (Department of Health 2019b). The comparability of these results is limited because of the differences between surveys (e.g. for reporting results on the PEC survey, it was decided that an average score of $80 \%$ across all items in the survey should be considered a positive patient experience).

Furthermore, our study revealed differences in positive care experiences across sociodemographic groups. In general, women reported lower proportions of positive experiences across all aspects of the care experience, except for that of a nurse giving easy-to-understand explanations. This result might be partly explained by the fact that Sibasa Clinic is a female nurse-led PHC facility. A different study in another nurse-led PHC facility highlighted the importance of nurse communication to a patient's satisfaction (and experience) (Nunu Munyewende 2017). It could be that nurse training on communicational skills in South Africa is lacking and failing to address the expectations and specific needs of female patients.

Although differences in sociodemographic groups were observed, these were not significant except when literacy status was considered. The proportion of literate respondents that reported positive experiences of care regarding a nurse spending enough time with a patient during consultation was significantly greater than that of illiterate respondents. However, after adjusting for other characteristics of the respondents, our results show that illiterate respondents were 2.6 times more likely to report a positive experience compared with a literate respondent. Studies have shown that more educated people (assuming literacy as a proxy for education) place a higher degree of importance on their interaction with the clinician and are less likely to report positive experiences than less educated patients (Rademakers et al. 2012). Our findings also suggest that illiterate populations may require special attention from the health care system. 
The adult literacy rate of South Africa is of 94.3\%; however, Limpopo's literacy rate (where Thulamela Municipality is located) shows one of the lowest adult literacy rates: $89.9 \%$ (Myburgh et al. 2005). This may require a diverse skill-set from health professionals, including nurses, at these PHC facilities to adapt their communication style to the characteristics of a patient.

Our results show that a previous negative experience at the clinic is a determinant of future positive experiences of care. Those who have had a previous negative experience at the clinic were more likely to report a current positive experience compared with those who have never had a negative experience at the clinic before. This could signal that one's expectations adjust after a previous negative consultation at the same provider. In addition, such negative encounters have been shown to affect patients' behaviour outside the clinical setting (Bayuo 2017; Schwei et al. 2016). For example, patients in Ghana have reported opting-out of care in their nearby and designated facilities due to negative experiences (Bayuo 2017). Other studies have identified other determinants of negative patient experience such as age, with younger patients being more likely to perceive a negative experience (Brito Fernandes et al. 2019; Xie et al. 2019). There were no significant results regarding this in our study.

The systematic measurement of patient experiences in South Africa is somewhat a novelty. The national survey on patient experiences covers many domains and results are reported as an average score (on a scale from 0 to $100 \%$ ). However, there are many methodological aspects of that survey that make results difficult to compare with those of other countries; hence, the importance of the use of a standardized set of questions on patient experiences, as those suggested by the OECD. To a limited extent, our results could be compared with those of the OECD's average of 11-19 countries. Our data show that the experiences of patients at the Sibasa Clinic regarding a nurse spending enough time in consultation (83.2 vs. $80.6 \%$ ) or providing easy-to-understand explanations ( 85.5 vs. $88.5 \%$ ) were similar to those of the OECD average (Statistics South Africa 2017). Greater differences were noticed on a nurse giving opportunity to ask questions or raise concerns (69.8 vs. $89.3 \%)$ and involving the patient in decision-making (77.1 vs. $83.6 \%)$ (Statistics South Africa 2017), signalling where improvement is needed the most.

\subsection{Strengths and limitations}

Our study was strengthened by the use of OECD's standardised PREMs with ambulatory care. Therefore, our results could be compared, to a limited extent, to those of other countries that used the same set of questions. Notwithstanding, our results should be considered in light of some limitations. The sample size and convenience sampling limited the ability to generalise findings to the Thulamela municipality, the country at large and our ability to contrast our results with those of other OECD countries with national representative samples. Also, the questions in our survey were presented as a binary response option, in contrast to the multipoint Likert answers suggested in OECD's survey. This was done to mimic the South African Department of Health's Patient Experience of Care standardised questionnaire and allow future comparisons. Finally, recollection of past negative experiences may have created a recall bias and affected respondents' responses on their current experiences of care.

\subsection{Policy implications and recommendations}

This study highlights the complexities of the patient-nurse relationship and the challenges posed by the sparse availability of data on patient experiences. These data can inform and support the 
decisions of clinic managers to strengthen patient-centred care. Our study identified that previous negative experiences of care and literacy status are focal points that require further attention. Notwithstanding, further studies are needed in South Africa, including more regions and larger sample sizes to generate more accurate data about patient experiences with ambulatory care.

\section{CONCLUSION}

Our results suggested that respondents expect to be given the opportunity to ask questions or raise concerns and be involved in decision-making about care and treatment. In general, respondents that were women, older (65 and over), with no paid job, educated and without a previous negative experience of care at the clinic were less likely to report a positive experience of care. These results at this PHC facility can inform the decisions of key stakeholders on aspects of the care experience that need greater improvement within the national framework for quality and safety assurance and patient experience measurement.

\section{ACKNOWLEDGEMENTS}

The authors would like to extend their appreciation to Sibasa Clinic and its staff for their cooperation. We are also grateful to the respondents in the study. The development and execution of the survey was funded by the South African Department of Higher Education and Training. The contribution of OBF, LG, NK and PB occurred within a Marie Skłodowska-Curie Innovative Training Network (HealthPros - Healthcare Performance Intelligence Professionals) that has received funding from the European Union's Horizon 2020 research and innovation programme under grant agreement Nr. 765141 (https://healthpros-h2020.eu). The funders had no role in study design, data collection and analysis, decision to publish, or preparation of the manuscript. Ethical clearance was obtained from the Limpopo Province Research and Ethics Committee of the Premier's office (REC-111513-038). Consent was obtained from all respondents involved. The answers of respondents were anonymized before analysis.

\section{REFERENCES}

Agency for Healthcare Research \& Quality [AHRQ] (2019): What is Patient Experience? https://www.ahrq. gov/cahps/about-cahps/patient-experience/index.html, accessed 25/08/2019.

Ahmed, F. - Burt, J. - Roland, M. (2014): Measuring Patient Experience: Concepts and Methods. The Patient 7(3): 235-241.

Bao, Y. - Fan, G. - Zou, D. - Wang, T. - Xue, D. (2017): Patient Experience with Outpatient Encounters at Public Hospitals in Shanghai: Examining Different Aspects of Physician Services and Implications of Overcrowding. PLoS One 12(2): e0171684.

Barbazza, E. - Kringos, D. - Kruse, I. - Klazinga, N., - Tello, J. (2019): Creating Performance Intelligence for Primary Health Care Strengthening in Europe. BMC Health Services Research 19: 1006.

Bayuo, J. (2017): Experiences with Out-patient Hospital Service Utilisation Among Older Persons in the Asante Akyem North District- Ghana. BMC Health Services Research 17(1): 5-11. 
Bleich, S. - Ozaltin, E. - Murray, C. (2009): How Does Satisfaction with the Health-Care System Relate to Patient Experience? Bulletin of the World Health Organization 87: 271-278.

Bresick, G. - Christians, F. - Makwero, M. - Besigye, I. - Malope, S. - Dullie, L. (2019a): Primary Health Care Performance: A Scoping Review of the Current State of Measurement in Africa. BMJ Global Health 4(Suppl. 8): e001496.

Bresick, G. - Sayed, A. R. - Le Grange, C. - Bhagwan, S. - Manga, N. (2015): Adaptation and Crosscultural Validation of the United States Primary Care Assessment Tool (expanded version) for Use in South Africa. African Journal of Primary Health Care and Family Medicine 7: e1-e11.

Bresick, G. F. - Sayed, A. R. - Le Grange, C. - Bhagwan, S. - Manga, N. - Hellenberg, D. (2016): Western Cape Primary Care Assessment Tool (PCAT) Study: Measuring primary care Organisation and Performance in the Western Cape Province, South Africa (2013). African Journal of Primary Health Care and Family Medicine 8: e1-e12.

Bresick, G. - von Pressentin, K. B. - Mash, R. (2019b): Evaluating the Performance of South African Primary cAre: A Cross-Sectional Descriptive Survey. South African Family Practice 61(3): 109-116.

Brito Fernandes, Ó. - Baji, P. - Kringos, D. - Klazinga, N. - Gulácsi, L. - Lucevic A. - Boncz, I. - Péntek, M. (2019): Patient Experiences with Outpatient Care in Hungary: Results of an Online Population Survey. The European Journal of Health Economics 20: 79.

Coulter, A. (2017): Measuring What Matters to Patients. BMJ 356: j816.

De Rosis, S. - Cerasuolo, D. - Nuti, S. (2020): Using Patient-Reported Measured to Drive Change in Healthcare: The Experience of the Digital, Continuous and Systematic PREMs Observatory in Italy. BMC Health Services Research 20: 315.

Department of Health (2017): National Guideline on Conducting Patient Experience of Care Survey in Public Health Establishments. Pretoria: Department of Health.

Department of Health (2019a): National Health Insurance Bill. Pretoria: Department of Health.

Department of Health (2019b): Health. South African Government. https://www.gov.za/about-sa/health, accessed 03/12/2019.

Doyle, C. - Lennox, L. - Bell, D. (2013): A Systematic Review of Evidence on the Links Between Patient Experience and Clinical Safety and Effectiveness. BMJ Open 3: e001570.

Dullie, L. - Meland, E. - Hetlevik, Ø. - Mildestvedt, T. - Gjesdal, S. (2018): Development and Validation of a Malawian Version of the Primary Care Assessment Tool. BMC Family Practice 19: 63-74.

Duschinsky, R. - Paddison, C. (2018): “The Final Arbiter of Everything”: A Genealogy of Concern with Patient Experience in Britain. Social Theory \& Health 16: 94-110.

Fujisawa, R. - Klazinga, N. (2017): Measuring Patient Experiences (PREMS): Progress Made by the OECD and Its Member Countries Between 2006 and 2016. OECD Health Working Paper 102.

Gilmore K. J. - Pennucci, F. - De Rosis, S. - Passino, C. (2019): Value in Healthcare and the Role of the Patient Voice. Healthcare Papers 18(4): 28-35.

Gulácsi, L. - Péntek, M. (2014): HTA in Central and Eastern European Countries; The 2001: A Space Odyssey and Efficiency Gain. The European Journal of Health Economics 15: 675-680.

Hunter, J. - Chandran, T. - Asmall, S. - Tucker, J. - Ntshengedzeni, R. (2017): South African Health Review 2017. Durban: Health Systems Trust.

Ivankovic D. - Poldrugovac, M. - Garel, P. - Klazinga, N. S. - Kringos, D. S. (2020): Why, What and How do European Healthcare Managers Use Performance Data? Results of a Survey and Workshop Among Members of the European Hospital and Healthcare Federation. PLoS One 15(4): e0231345.

Kelly, G. -Mrengqwa, L. -Geffen, L et al. (2019): “They Don't Care About Us”: Older People’s Experiences of Primary Healthcare in Cape Town, South Africa. BMC Geriatrics 19: 98. 
Kingsley, C. - Patel, S. (2017): Patient-reported Outcome Measures and Patient-reported Experience Measures. BJA Education 17(4): 137-144.

LaVela, S. - Gallan, A. (2014): Evaluation and Measurement of Patient Experience. Patient Experience 1(1): $28-36$.

Llanwarne, N. - Abel, G. - Elliot, M. - Paddison, C. - Lyratzopoulos, G. - Campbell, J. et al. (2013): Relationship Between Clinical Quality and Patient Experience: Analysis of Data from the English Quality and Outcomes Framework and the National GP Patient Survey. Annals of Family Medicine 11(5): 467-472.

Lucevic, A. - Péntek, M. - Kringos, D. - Klazinga, N. - Gulácsi, L. - Brito Fernandes, Ó. - Boncz, I. - Baji, P. (2019): Unmet Medical Needs in Ambulatory Care in Hungary: Forgone Visits and Medications from a Representative Population Survey. European Journal of Health Economics 20: 71-78.

Manga, N. - Harding, R. - De Sa, A. - Murie, K. - Namane, M. - Raubenheimer, P. (2018): Development and Validation of a Tool to Measure Patient Experience in Chronic Disease Care. African Journal of Primary Health Care \& Family Medicine 10: 6.

McLaren, Z. - Ardington, C. - Leibbrandt, M. (2014): Distance Decay and Persistent Health Care Disparities in South Africa. BMC Health Services Research 14: 541.

Monson, J. (2006): South African Child Gauge 2006. Cape Town: Children's Institute, University of Cape Town.

Mukiapini, S. - Bresick, G. - Sayed, A. R. - Le Grange, C. (2018): Baseline Measures of Primary Health Care Team Functioning and Overall Primary Health Care Performance at Du Noon Community Health Centre. African Journal of Primary Health Care \& Family Medicine 10: 1458.

Myburgh, N. -Solanki, G. -Smith, M. -Lalloo, R. (2005): Patient Satisfaction with Health Care Providers in South Africa: The Influences of Race and Socioeconomic Status. International Journal for Quality in Health Care 17(6): 473-477.

Nunu, W. - Munyewende, P. (2017): Patient Satisfaction with Nurse-delivery Primary Health Care Services in Free State and Gauteng Provinces, South Africa: A Comparative Study. African Journal of Primary Health Care \& Family Medicine 9(1): 1-8.

OECD (2014): OECD Health Statistics 2014: How Does South Africa Compare? Paris: OECD. https://www. oecd.org/els/health-systems/Briefing-Note-SOUTH-AFRICA-2014.pdf, accessed 15/12/2019.

OECD (2017): Ministerial Statement. The Next Generation of Health Reforms. OECD Health Ministerial Meeting. Paris.

OECD (2019a): Health Status: Infant Mortality Rates. https://data.oecd.org/healthstat/infant-mortalityrates.htm, accessed 15/12/2019.

OECD (2019b): How's life in South Africa. Paris: OECD. https://www.oecd.org/statistics/Better-LifeInitiative-country-note-South-Africa.pdf, accessed 15/12/2019.

OECD (2019c): Health Status: Life Expectancy at Birth. https://data.oecd.org/healthstat/life-expectancy-atbirth.htm, accessed 15/12/2019.

OECD - European Commission (2019): Health at a Glance: Europe 2019. Paris: OECD Publishing.

Peltzer, K. (2009): Patient Experiences and Health System Responsiveness in South Africa. BMC Health Services Research 9: 117.

Peltzer, K. - Phaswana-Mafuya, N. (2012): Patient Experiences and Health System Responsiveness Among Older Adults in South Africa. Global Health Action 5: 18545.

Péntek, M. (2019): Patient-reported Outcomes: Opportunities and Challenges in Central Europe. The European Journal of Health Economics 20: 1-3. 
President's Cancer Panel (2018): Promoting Value, Affordability, and Innovation in Cancer Drug Treatment. A Report to the President of the United States. Washington: President's Cancer Panel.

Price, R. - Elliott, M. - Zaslavsky, A. - Hays, R. - Lehrman, W. - Rybowski, L. (2014): Examining the Role of Patient Experience Surveys in Measuring Health Care Quality. Medical Care Research and Review 71(5): 522-554.

Rademakers, J. - Delnoij, D. - Nijman, J. - de Boer, D. (2012): Educational Inequalities in Patient-centred Care: Patients' Preferences and Experiences. BMC Health Services Research 12(1): 2.

Sandager, M. - Freil, M. - Knudsen, J. (2016): Please Tick the Appropriate Box: Perspectives on Patient Reported Experience. Patient Experience Journal 3: 63-79.

Schwei, R. - Johnson, T. - Matthews, A. - Jacobs, E. (2016): Perceptions of Negative Health-care Experiences and Self-reported Health Behavior Change in Three Racial and Ethnic Groups. Ethnicity \& Health 22(2): 15-168.

Statistics South Africa (2011): Thulamela Statistics. http://www.statssa.gov.za/?page_id=993\&id=thulamelamunicipality, accessed 16/03/2019.

Statistics South Africa (2017): General Household Survey 2017. Pretoria: Statistics South Africa.

Wolfe, J. - Niederhauser, V. - Marshburn, D. - LaVela, S. L. (2014): Defining Patient Experience. Patient Experience Journal 1(1):7-19.

WHO (2018): Pricing of Cancer Medicines and Its Impacts. Geneva: WHO.

Xie, J. - Hu, Y. - Lu, C. - Fu, Q. - Carbone, J. - Wang, L. et al. (2019): What Are the Risk Factors of Negative Patient Experience? A Cross-Sectional Study in Chinese Public Hospitals. INQUIRY: The Journal of Health Care Organization, Provision, and Financing 56: 1-7.

Xu, K. - Evans, D. -Carrin, G. -Aguilar-Rivera, M. (2005): Designing Health Financing Systems to Reduce Catastrophic Health Expenditure. Geneva: WHO.

Open Access. This is an open-access article distributed under the terms of the Creative Commons Attribution 4.0 International License (https://creativecommons.org/licenses/by/4.0), which permits unrestricted use, distribution, and reproduction in any medium, provided the original author and source are credited, a link to the CC License is provided, and changes - if any - are indicated. (SID_1) 